\title{
Macro and Microscopic Gastroprotective Effects of Grape Seed Extract on the Gastric
} Ulcer Experimentally Induced by Alcohol

\author{
Muhammad A. Algebali ${ }^{* a, b}$, Esther T. Menze ${ }^{b}$, Iriny M. Ayoub ${ }^{c}$, Mariane G. Tadros ${ }^{b}$, Ahmed Esmat $^{b}$ \\ ${ }^{a}$ Pharmacology Department, Faculty of pharmacy, Omar Al-Mukhtar University, Libya \\ ${ }^{\mathrm{b}}$ Department of Pharmacology and Toxicology, Faculty of Pharmacy, Ain Shams University, Cairo 11566, Egypt \\ ${ }^{\mathrm{c}}$ Department of Pharmacognosy, Faculty of Pharmacy, Ain Shams University, Cairo 11566, Egypt
}

\begin{abstract}
Alcohol administration has been widely correlated with gastric injuries involving gastric ulcers. Grape seed extract (GSE) is a rich source of phenolics and flavonoids with marked antioxidant and antiinflammatory characteristics that might give it a potential impact on the gastric ulcer. Polyphenolics are naturally occurring antioxidants that protect our bodies from ROS damage and their intake has probable health advantages involving protection from many ailments. Thus, this study intended to illustrate the probable protective actions of grape seed extract against alcohol induced gastric ulcers in rats. The total phenolics and the total flavonoids content in grape seed extract have been quantified. The total phenolic content was found to be $284.11 \pm 0.01 \mathrm{mg}$ of gallic acid equivalent (GAE) per $\mathrm{g}$ of grape seed extract. Meanwhile, the total flavonoid content was $8.02 \pm 0.08 \mathrm{mg}$ of quercetin equivalent $(\mathrm{QE}) / \mathrm{g}$ extract. Pretreatment with grape seed extract $\left(100 \mathrm{mg} \mathrm{kg}^{-1}\right.$ p.o.) reduced the serious effect of alcohol gastric mucosal damage as illustrated by decreasing the size of macroscopic lesions and alleviating the histopathologic aberrations. These studies were similar to those applied by the standard antiulcer omeprazole. These results could be ascribed to the antioxidant action of grape seed extract as it notably restored the gastric catalase level to the normal range. These outcomes highlight the protection effects of grape seed extract on the gastric ulcer induced by alcohol.
\end{abstract}

Keywords: Grape extract; GE, alcohol; gastric ulcer; oxidative stress.

*Correspondence | Muhammad A. Algebali; Pharmacology Department, Faculty of pharmacy, Omar Al-Mukhtar University, Libya.

Email: m.albary90@yahoo.com

Citation | Algebali MA, Menze ET, Ayoub IM, Tadros MG, Esmat A, 2020. Macro and Microscopic Gastroprotective Effects of Grape Seed

Extract on the Gastric Ulcer Experimentally Induced by Alcohol. Arch Pharm Sci ASU 4(1): 113-123

DOI: $10.21608 /$ APS.2020.2003.1040

Print ISSN: 2356-8380. Online ISSN: 2356-8399.

Received 13 April 2020. Accepted 13 June 2020.

Copyright: ${ }^{\circledR} 2020$ Algebali et al. This is an open-access article licensed under a Creative Commons Attribution 4.0 International License (CC BY 4.0), which permits unrestricted use, distribution, and reproduction in any medium, provided the original author(s) and source are credited. Published by: Ain Shams University, Faculty of Pharmacy

\section{INTRODUCTION}

The gastric layers are permanently exposed to potentially harmful compounds, gastric acid, and enzymes, but the stomach due to bicarbonate secretion, growth factors for cellular regeneration and circulation and the tight junction composition between its cells all these factors could preserve its structural and functional safety $[\mathbf{1 ,} 2]$. However, many factors can induce gastric lesions when they overcome mucosal defense mechanisms. Gastric lesions are mostly due to infection with Helicobacter pylori (H pylori), nonsteroidal anti-inflammatory drugs (NSAIDs), alcohol drinking, and tobacco smoking [3, 4]. Intake a lot of ethanol causes necrotic lesions in 
the mucosal layer of the stomach by producing acute hemorrhagic lesions, mucosal edema, inflammatory cell infiltration, that lead to weakened defensive agents like $\mathrm{HCO}_{3}{ }^{-}$secretion and mucus production [5, 6]. Thus, alcoholinduced gastric injury is a valuable design for the estimate of alcohol-induced pathological variations in gastric mucosa [6, 7]. The mechanisms dependent on alcohol-induced gastric ulcers have not been completely known, yet. Increasing signals have indicated that oxidative stress plays a crucial function in its pathogenesis $[\mathbf{8}, 9]$. The experimental form of alcohol-induced gastric injury reflects various characteristics of the human state and affords a way for evaluating factors with latent anti-ulcer action beside its linked pathways for gastric protection [10]. Agents with antioxidant properties were proved to have valuable effects in the protection from alcohol-induced gastric lesions [10, 11]. Flavonoids are natural polyphenolic substances that can protect our bodies from ROS-evoked damage and their usage has probable advantages involving protection from many ailments $[\mathbf{8}, \mathbf{1 2}, \mathbf{1 3}]$. The grape seed extract of the European red grape is very rich with antioxidant phenolics and flavonoids [14]. Therefore, the current study aims at investigating the potential gastroprotective actions of the grape seed extract on the alcohol-induced ulcer. We have used the lowest effective grape extract dose and numbers of administration that could efficiently protect the stomach from gastric lesions induced by alcohol according to previously mentioned studies $[\mathbf{1 5}, \mathbf{1 6}]$.

\section{MATERIAL AND METHODS}

\subsection{Animals}

Forty Sprague-Dawley rats (190-210 g). Bought from the Institute of National Research, Cairo, Egypt all animals kept at a precise temperature of $24 \pm 2{ }^{\circ} \mathrm{C}$, exposed to $12 / 12$ h dark-light cycles, and standard pellet diet and tap water ad libitum were introduced to them. Animal experimental methods implemented in agreement with the "ARRIVE" guidelines and conformity with U.K. Animals Act, 1986. "The Committee of Animal Care and Use" approved the current protocol - in advance -, Faculty of Pharmacy, Ain Shams University (Approval \#: 180).

\subsection{Chemicals and plant material}

The grape seed extract was procured from Hangzhou Joy more Technology Co Ltd, China (95\%, purity), while omeprazole was purchased from Sigma pharmaceutical, Egypt. For standardization of grape seed extract, Folin Ciocalteu reagent, methanol (HPLC analytical grade), reference standards of quercetin and gallic acid were obtained from Merck (St Louis, MO, USA). All other compounds were of the highest analytical grade.

\subsection{Quantification of total phenolics}

A spectrophotometric technique was adopted for the assessment of total phenolics in grape seed extract using Folin-Ciocalteau reagent [17]. The assay was carried out in triplicate. Gallic acid was used as a standard at a concentration range (80-280 $\mu \mathrm{g} / \mathrm{mL})$ to construct the calibration curve. Total phenolic content was expressed as mg gallic acid equivalent (GAE)/g grape seed extract.

\subsection{Quantification of Total flavonoids}

A spectrophotometric method was conducted to assess the total flavonoids content in grape seed extract using aluminum chloride reagent $[17,18]$. The assay was done in triplicate. Quercetin was used as a standard (concentration range of 5 to $100 \mu \mathrm{g} / \mathrm{mL}$ ) to construct a calibration curve. The total flavonoid content was assessed as mg quercetin equivalent $(\mathrm{QE}) / \mathrm{g}$ grape seed extract. 


\subsection{Induction of gastric ulcer}

Gastric lesions caused using only one intragastric dose of absolute ethanol (96\%) $(5 \mathrm{~mL}$ $\mathrm{kg}^{-1}$ ) that was given by orogastric intubation as illustrated before $[8, \mathbf{1 1}, \mathbf{1 9}, \mathbf{2 0}]$. The control group was administered an equal volume of normal saline rather than alcohol. Animals have fasted for $16 \mathrm{~h}$ before any treatment with free access to water.

\subsection{Experimental design}

Rats were randomly assigned to five groups, each comprising eight rats $(n=8)$. Group I (Control group): normal rats received oral normal saline. Group II (alcohol group): administrated a single intragastric dose of ethyl alcohol 96\% (5 $\mathrm{mL} \mathrm{kg}^{-1}$ ). Group III (standard): received only one intragastric dose of alcohol and omeprazole dose (40 $\mathrm{mg} \mathrm{kg}^{-1}$ ) $1 \mathrm{~h}$ prior ulcer induction. Group IV (alcohol + grape seed extract) oral grape seed extract (100 mg kg-1/day) for 6 days and 1 hour after the final dose received only one intragastric dose of alcohol. Group V (grape seed extract): normal rats that received oral grape seed extract (100 $\mathrm{mg} \mathrm{kg}^{-1} /$ day) only for 6 days dissolved in normal saline.

\subsection{Tissue collection and preparation}

Rats were sacrificed $1 \mathrm{~h}$ after alcohol dose and their stomachs were surgically removed, the opening was made along with the greater curvature and the stomachs were rinsed by saline to clean them from their contents and blood clots. Stomachs dried, scrutinized by microscope for any gastric lesion (ulcer index expression) and photographed for subsequent assessment of the gastric lesions. Then, the stomachs were divided into two moieties, one was put in $10 \%$ formaldehyde in buffered saline for histopathologic evaluation while the remaining gastric tissue was divided into 3 parts and kept at $-80{ }^{\circ} \mathrm{C}$ for the biochemical requirements.

\subsection{Macroscopic examination}

Each stomach was opened and rinsed with saline to look at the morphological alternations caused by different treatments. Pictures were taken using a high-performance camera. Ulcer index was calculated as a mean of ulcer scores. The scoring of ulcers was described as follows: " 0 " for the normal colored stomach, "'0.5" for red coloration, "1" for spot ulcer, "1.5" for hemorrhagic streaks, "2" for ulcer between 3-5 $\mathrm{mm}$ and " 3 " for ulcer $>5 \mathrm{~mm}$.

\subsection{Histopathologic examination}

Stomach tissue samples from the different groups were immersed in $10 \%$ formalin for $24 \mathrm{~h}$, rinsed first with tap water and after that, graded series of alcohol (70\%, 90\% then 96\%) to dehydrate all tissues, then paraffin beeswax tissue blocks were prepared. The obtained tissue sections $(4 \mu \mathrm{m})$ were fixed on slides and stained by hematoxylin and eosin stain for routine examination using light microscopy [21].

\subsection{Determination of mucosal mucin content}

Mucosal mucin content was assessed in tissue homogenate using a specific ELISA kit (catalog \#: MBS076266, MyBioSource, USA) based on the quantitative sandwich technique. The results were expressed as $\mu \mathrm{g} / \mathrm{mg}$ protein.

\subsection{Determination of oxidative and inflammatory biomarkers}

Catalase activity was assayed according to the manufacturer instructions (catalog \#: CA-2516, Biodiagnostics, Giza, Egypt). Briefly, $50 \mu \mathrm{L}$ of tissue homogenate $(10 \% \mathrm{w} / \mathrm{v})$ was added to an identified amount of $\mathrm{H}_{2} \mathrm{O}_{2}$. Then, the reaction was stopped with a catalase inhibitor after precisely $1 \mathrm{~min}$. The remaining $\mathrm{H}_{2} \mathrm{O}_{2}$ reacts with two reagents: 3,5-dichloro-2-hydroxybenzene sulfonic acid (DHSB) and 4- aminophenazone to form a pink color detected at $510 \mathrm{~nm}$ whose 
intensity is inversely proportional to the amount of catalase in the sample. Catalase activity was expressed as $\mathrm{U} / \mathrm{mg}$ protein. Reduced glutathione (GSH) content was measured according to the kit's instructions (catalog \#: GR-2510, Biodiagnostics, Giza, Egypt), based on the reduction of 5,5 dithiobis (2 - nitrobenzoic acid) (DTNB) with glutathione (GSH) to produce a yellow compound. Optical density was measured at $405 \mathrm{~nm}$. The results were expressed as $\mathrm{nmol} / \mathrm{mg}$ protein.

Nitric oxide concentration - as a biomarker linking both oxidative stress and inflammation was determined in gastric tissue homogenate using a biochemical kit (catalog \#: NO-2532, Biodiagnostics, Giza, Egypt). The assay depends on the formation of azo dye between nitrous acid, sulphanilamide, and N-(1-naphthyl) ethylenediamine that can be measured colorimetrically at wavelength $540 \mathrm{~nm}$. The results were expressed as nmol/mg protein. Moreover, the inflammatory cytokine Interleukin-6 (IL-6) was measured by a specific ELISA kit (catalog \#: BMS625, Thermo Fisher Scientific, Austria), based on the quantitative sandwich technique. The results were expressed as $\mathrm{pg} / \mathrm{mg}$ protein.

\subsection{Protein content detection}

Protein contents were determined using the BCA protein assay kit (Biovision Inc, USA).

\subsection{Statistical analysis}

Normally distributed data analyzed with oneway ANOVA using Tukey's post hoc test. Nonparametric data were analyzed with Kruskal Wallis followed by Dunn test. All statistical analyses were done using GraphPad Prism software (version 8, ISI ${ }^{\circledR}$ software, USA). Statistical significance was accepted at a $\mathrm{p}<0.05$. The results were presented as mean \pm SEM.

\section{RESULTS}

\subsection{Total phenolics and total flavonoids}

\section{content of grape seed extract}

In the current study, the total phenolics and the total flavonoids content in grape seed extract were quantified as gallic acid and quercetin equivalents, respectively. The total phenolic content in grape seed extract was found to be $284.11 \pm 0.01 \mathrm{mg}$ of gallic acid equivalent (GAE) per $g$ of grape seed extract. The total flavonoid content in grape seed extract was $8.02 \pm 0.08 \mathrm{mg}$ of quercetin equivalent $(\mathrm{QE}) / \mathrm{g}$ powdered plant material. Results observed herein were consistent with previous reports [22-24].

\subsection{Macroscopic examination of the gastric mucosa of rats treated with alcohol}

Macroscopic reflection indicated that pretreatment with grape seed extract $\left(100 \mathrm{mg} \mathrm{kg}^{-1}\right)$ (Fig. 1 and Table 1) or omeprazole (Fig. 1C) considerably reduced gastric mucosal injuries compared to the alcohol-treated group, where showed longed bloody streaks injuries ranging from 1-6 mm in length (Fig. 1B). The normal control group displays the normal morphology of stomach tissue without any injuries (Fig. 1A). Ethanol-induced significant increase in the ulcer score compared to the control group, while pretreatment with grape seed extract significantly attenuated this effect. There was no significant difference between grape seed extract and omeprazole.

\subsection{Effect of pretreatment with grape seed extract on mucosal mucin content in alcohol- treated rats}

Alcohol-induced a significant decrease in mucin levels by $64 \%$ as compared to the control group. These levels were reverted by grape seed extract $\left(100 \mathrm{mg} \mathrm{kg}^{-1}\right)$ pretreatment that increased mucin levels by $55 \%$ compared to the alcoholtreated rats (table 1).

There was no significant difference between the effect of omeprazole and the grape seed extract. 


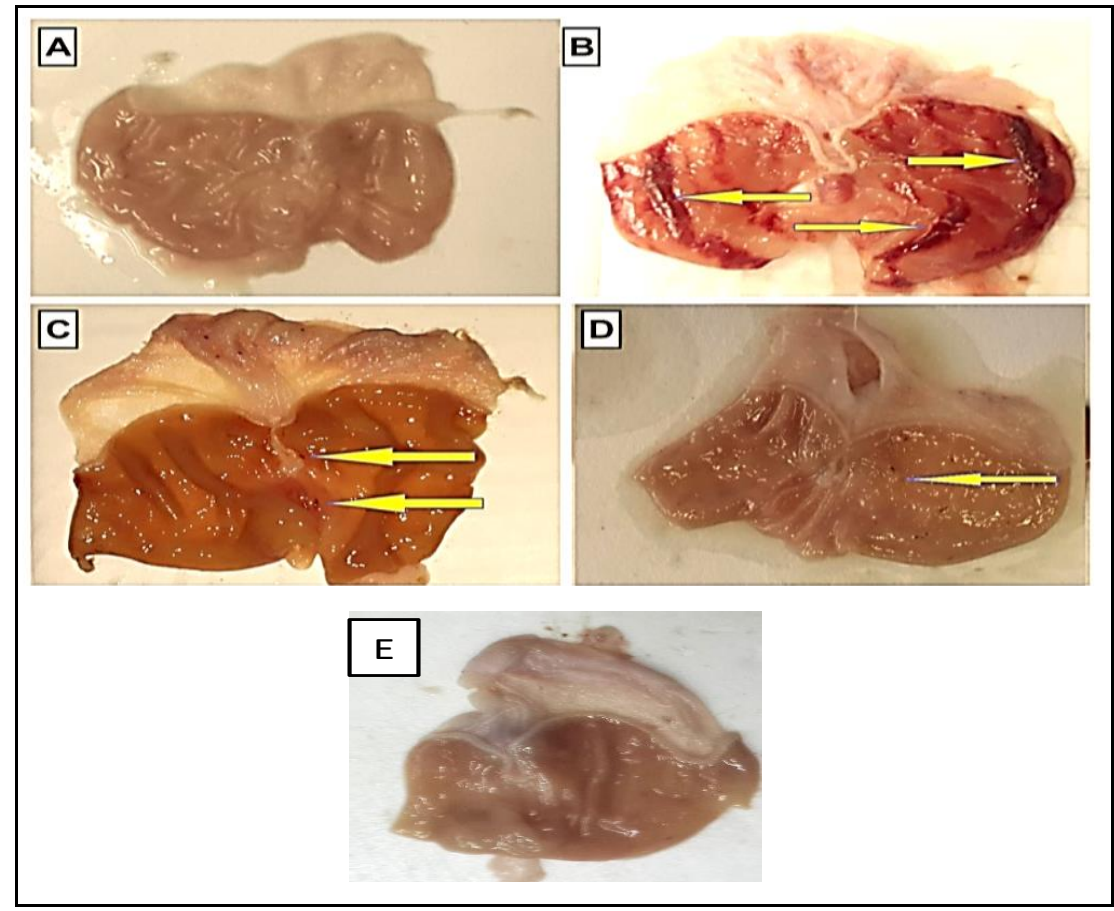

Fig. 1. Macroscopic examination of the gastric mucosa. (A) Normal control group, (B) alcohol-induced ulcer group, (C) omeprazole $\left(40 \mathrm{mg} / \mathrm{kg}\right.$ ) pretreated group, (D) grape seed extract $\left(100 \mathrm{mg} \mathrm{kg}^{-1}\right)$ pretreated group. (E) grape seed extract only treated group

Table 1. Effect of pretreatment with grape seed extract on ulcer score and mucin content in an experimental model of gastric ulceration induced by alcohol

\begin{tabular}{|c|c|c|}
\hline Group & Ulcer score & $\begin{array}{l}\text { Mucin content } \\
\mu \mathrm{g} / \mathrm{mg} \text { protein }\end{array}$ \\
\hline (A) Control & $0(0,0)$ & $102 \pm 5.9$ \\
\hline (B) Alcohol-induced ulcer & $4^{\mathrm{a}}(1.5,3.7)$ & $36^{\mathrm{a}} \pm 2.8$ \\
\hline (C) Omeprazole pretreated & $1.9^{\mathrm{b}}(0.6,1.7)$ & $72^{\mathrm{a}, \mathrm{b}} \pm 2.5$ \\
\hline $\begin{array}{l}\text { (D) Grape seed extract }(100 \mathrm{mg} \\
\left.\mathrm{kg}^{-1}\right) \text { pretreated. }\end{array}$ & $1.2^{\mathrm{b}}(0,0.9)$ & $59^{\mathrm{a}, \mathrm{b}} \pm 3.1$ \\
\hline $\begin{array}{l}\text { (E) Grape seed extract only } \\
\text { treated }\end{array}$ & $0(0,0)$ & $97^{\mathrm{b}} \pm 6.5$ \\
\hline
\end{tabular}

Data of ulcer score are presented as medians and interquartile range and analyzed by using Kruskal Wallis followed by Dunn as a post-hoc test. Data of mucin levels were expressed as mean \pm SEM and were analyzed using one-way ANOVA followed by Tukey as post hoc test. a and b; statistically significant from control and alcohol groups, respectively at $\mathrm{p}<0.05$ 


\subsection{Effect of the grape seed extract on stomach histological features}

Gastric tissues from a group of rats kept as a control did not show any histopathological modification and the histological structure of mucosa, submucosa, muscularis and serosa showed normal as presented in (Fig. 2A). In contrast, alcohol-treated rats showed focal necrosis, ulceration, and hemorrhage in the mucosal layer associated with edema and few inflammatory cells infiltration in the submucosa while the muscularis and serosa were intact (Fig. 2B). Groups pretreated with omeprazole (Fig. 2C) or grape seed extract $\left(100 \mathrm{mg} \mathrm{kg}^{-1}\right)$ (Fig. 2D) showed mild edema with few inflammatory cell infiltrations in the submucosa.

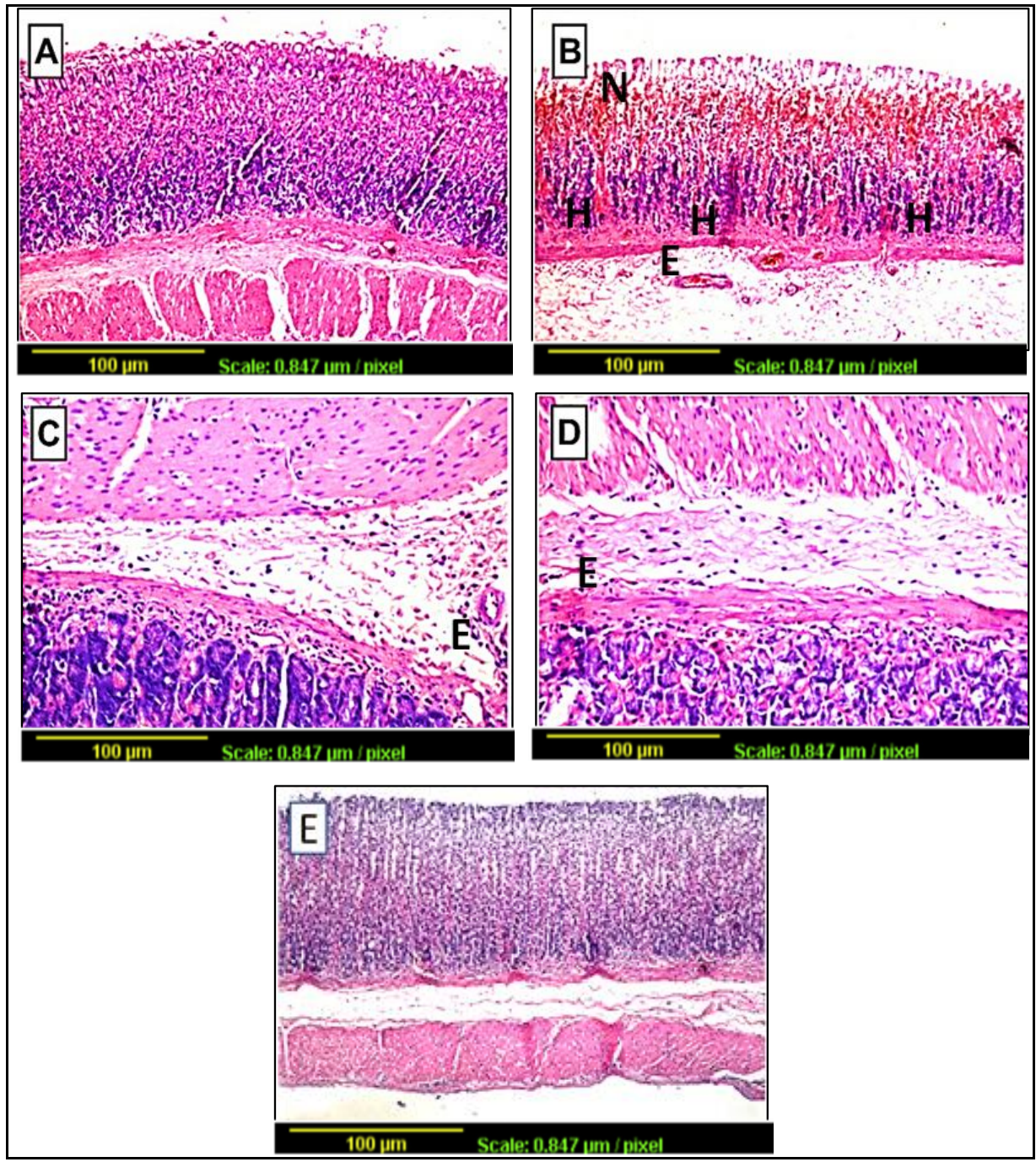

Fig. 2. Effect of pretreatment with grape seed extract on the alcohol-induced histological alternation of the gastric tissue. Photomicrographs of haematoxylin and eosin-stained sections of the stomach from the control group (A), control (B), alcoholtreated group (C), omeprazole-pretreated group $\left(40 \mathrm{mg} \mathrm{kg}^{-1}\right)$ (D) grape seed extract-pretreated group (100 mg/kg) and (E), grape seed extract only-treated group. with $40 x$ magnification power. $(\mathrm{H}=$ haemorrhage, $\mathrm{E}=$ oedema, $\mathrm{N}=$ necrosis $)$

\subsection{Effect of pretreatment with grape seed extract on the biomarkers of oxidative stress and inflammation in alcohol-treated rats}

As indicated in (Fig. 3A \& 3B), ethanolinduced oxidative alterations in gastric tissue as manifested by the significant (3-fold) rise of 
catalase enzymatic activity and depletion of GSH content by $83 \%$, as compared to the corresponding control group. These effects were ameliorated by grape seed extract $\left(100 \mathrm{mg} \mathrm{kg}^{-1}\right)$ pretreatment that decreased catalase activity by $62.8 \%$ and increased GSH content by 2.6 folds compared to the alcohol-exposed rats. Moreover, nitric oxide was assessed as nitrite concentration as an important biomarker of oxidative stress and inflammation that plays a vital role in ulcer healing. As shown in (Fig. 3C), ethanol significantly decreased nitrite concentration by about $66 \%$ in comparison to the control group. On the contrary, pretreatment with by grape seed extract (100 mg kg $\mathrm{g}^{-1}$ ) significantly raised nitrite concentration by about two folds, compared to the ethanol-exposed group. Gastric tissue inflammation was further confirmed by the significant increase of the cytokine "IL-6" by more than two folds, compared to the control animals as displayed in (Fig. 3D). Again, pretreatment with grape seed extract $(100 \mathrm{mg} \mathrm{kg}$ $\left.{ }^{1}\right)$ significantly ameliorated such effect by about $50 \%$ compared to the ethanol-exposed group.

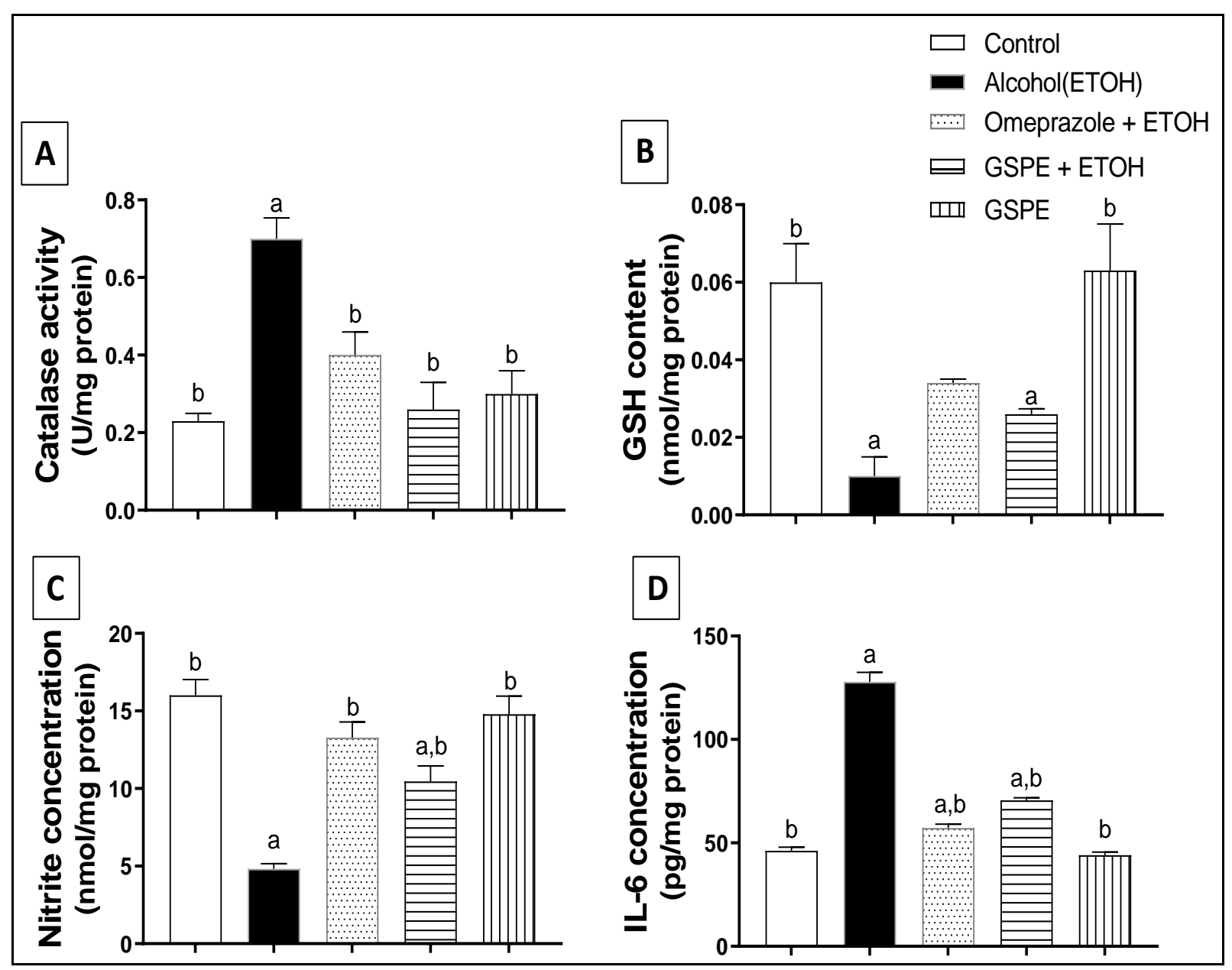

Fig. 3. Effect of pretreatment with grape seed extract on: (A) CAT activity, (B) GSH content, (C) Nitric Oxide assessed as nitrite concentration and (D) IL-6 concentration, in an experimental model of gastric ulceration induced by alcohol.

Data are presented as mean \pm SEM $(n=6)$ where: $a$ and $b$; statistically significant from control and alcohol groups, respectively at $\mathrm{p}<0.05$ using one-way analysis of variance (ANOVA) followed by Tukey as a post-hoc test. 


\section{DISCUSSION}

Medicinal plants are the origin of some familiar antiulcer medications such: liquorice (dehydroglycerrizinic acid), Emblica Officinalis (embline), and Terminalia chebula [25]. The current study was carried out to illustrate the gastroprotective effect of grape seed extract on the gastric ulcer models primarily caused by oxidative stress, focus on its potential antioxidant and anti-inflammatory actions. The grape seed extract is a mixture of biologically active polyphenolic compounds including flavonoids and oligomeric proanthocyanidins [25, 26]. Various properties of grape seed extract have been presented in many experimental studies such; vasodilator, anticarcinogenic, antiallergic, anti-inflammatory, antibacterial, antiviral, and immunomodulator in addition to its ROS scavenging and antioxidant characteristics [27]. The alcohol-induced gastric lesion is a main experimental model frequently used for the preclinical estimate of factors with potential gastroprotective activity because alcohol has been listed as a higher cause of gastric ulcer [10, 11]. It was observed that alcohol consumption modified the gastric mucosa and submucosa and caused some lesions. These lesions are cooccurred by edema, epithelial and vascular cell alteration, leucocytes infiltration of the submucosal layer, and necrosis. Our results are in line with preceding reports using alcohol as an inducer of the peptic ulcer [28]. Numerous mechanisms are associated with the progression of alcohol-induced mucosal lesions [29]. The effect of alcohol on gastric mucosa could be due to the disturbed balance between gastric mucosal defensive and destructive agents [30]. Alcohol causes induce microcirculatory disturbance with hypoxia, linking to the overproduction of ROS [30]. Pretreatment with grape seed extract protects from gastric lesions caused by alcohol consumption and provided the decline of morphological and histopathological observed marks. Oxidative stress, identified by an imbalance between oxidants and antioxidants in partiality of oxidants, guides to disturbance of redox signaling and physiological function [31]. ROS formed under oxidative stress is associated with to damage all cellular bio-molecules (sugars, lipids, polynucleotides, and proteins,) [32]. Thus, various defense systems have been activated intracellularly to inhibit unrestrained ROS extension. These systems involve nonenzymatic molecules (glutathione, antioxidant vitamins like $\mathrm{C}$, and $\mathrm{E}$, and many antioxidants existing in diets) besides enzymatic scavengers of ROS. Enzymes like superoxide dismutase (SOD), catalase (CAT), and glutathione peroxidase (GPX) are the most popular protection systems [33]. Catalase is an endogenous antioxidant enzyme, prevents cell damage induced by ROS [34]. We noted in the current study that alcohol intoxication induced alteration in catalase activity. Alcohol administration produced oxidative imbalance through various pathways including the production of ROS [35]. In this study, alcohol elevated the activity of catalase enzyme that might be increased as a compensatory mechanism due to increased levels of ROS [32].

The previous results suggest that grape seed extract might represent a promising pharmacological drug in gastric ulcer treatment, in a manner comparable to that exerted by omeprazole, with potential antioxidant properties.

\section{Conclusion}

In conclusion, the present study provides evidence for the therapeutic effects of the grape seed extract on alcohol-induced gastric ulcers in which it acts as a gastroprotective agent before ulcer induction. Further studies may be done to determine the optimum therapeutic dose of grape seed extract, which poses the highest effect and the lowest side effects. 


\section{Declarations}

The authors declare that they have no known competing financial affairs or personal relations that could have looked to influence the work reported in this paper.

\section{Ethics Approval and Consent to Participate}

Ain Shams University Faculty of Pharmacy Review Committee approved the study protocol for the use of animal subjects under the memorandum No.180 in 27/2/2018.

\section{Consent to publish}

Not applicable

\section{Availability of Data and Materials:}

All data generated or analyzed during this study are included in this published article in the main manuscript.

\section{Competing interests}

The authors declare that no competing interests exist.

\section{Funding Statement}

No funding source was received.

\section{Authors' contributions}

The experiment was conceived and designed by E.T.M., A.E. and M.G.T. Procedures were performed and chemicals were purchased by M.A. Standardization of the plant extract was performed by I.M.A. The manuscript was drafted and written by M.A. and contributed to revising the manuscript. All authors have read and approved the final manuscript.

\section{Acknowledgment}

The authors would like to acknowledge all colleagues in the Department of Pharmacology and Toxicology, Faculty of Pharmacy, Omar AlMukhtar University, and the Department of Pharmacology and Toxicology, Faculty of Pharmacy, Ain Shams University for their help.

\section{List of abbreviations}

Grape seed extract, GSE; Reactive oxygen species, ROS; Ulcer index, UI; Ethyl alcohol, ETOH; Omeprazole, Omp; Catalase, CAT; Glutathione peroxidase, GPX; Superoxide dismutase SOD.

\section{REFERENCES}

1. Flemstrom, G. and J.I. Isenberg, Gastroduodenal mucosal alkaline secretion and mucosal protection. Physiology, 2001. 16(1): p. 23-28.

2. Malik, T.F., and K. Singh, Peptic ulcer disease, in StatPearls [Internet]. 2019, StatPearls Publishing.

3. Franke, A., S. Teyssen, and M.V. Singer, Alcohol-related diseases of the esophagus and stomach. Digestive Diseases, 2005. 23(34): p. 204-213.

4. Laine, L., K. Takeuchi, and A. Tarnawski, Gastric mucosal defense and cytoprotection: bench to bedside. Gastroenterology, 2008. 135(1): p. 41-60.

5. Lim, J.M., et al., Protective effects of a triple-fermented barley extract (FB e) against $\mathrm{HC}$ 1/Et $\mathrm{OH}$-induced gastric mucosa damage in mice. Food Science \& Nutrition, 2018. 6(8): p. 2036-2046.

6. Lanas, A. and F.K. Chan, Peptic ulcer disease. Lancet, 2017. 390(10094): p. 613624.

7. Simões, S., Lopes, R., Campos, M.C.D., Marruz, M.J., da Cruz, M.E.M. and Corvo, L., Animal models of acute gastric mucosal injury: Macroscopic and microscopic evaluation. Animal models and experimental medicine 2019., 2(2): pp.121-126.

8. Al Batran, R., Al-Bayaty, F., Al-Obaidi, M.M.J., Abdualkader, A.M., Hadi, H.A., Ali, H.M. et al. In vivo antioxidant and antiulcer 
activity of Parkia speciosa ethanolic leaf extract against an ethanol-induced gastric ulcer in rats. PloS one, 2013.8(5).

9. VRHOVSEK, U., M. GASPEROTTI, and F. MATTIVI, Ellagitannins from Rubus berries for the control of gastric inflammation: in vitro and in vivo studies. PLoS One, 2013.

10. Santos, F. and V. Rao, 1, 8-cineol, a food flavoring agent, prevents ethanol-induced gastric injury in rats. Digestive diseases and sciences, 2001. 46(2): p. 331-337.

11. Liu, Y., Tian, X., Gou, L., Fu, X., Li, S., Lan, $\mathrm{N}$, et al., Protective effect of 1-citrulline against an ethanol-induced gastric ulcer in rats. Environmental toxicology and pharmacology, 2012. 34(2): p. 280-287.

12. Rehman, M.U., Tahir, M., Khan, A.Q., Khan, R., Lateef, A., Hamza, O.O., et al., Diosmin protects against trichloroethylene-induced renal injury in Wistar rats: plausible role of p53, Bax and caspases. British journal of nutrition, 2013. 110(4): p. 699-710.

13. Yun, S., Chu, D., He, X., Zhang, W. and Feng, C., Protective effects of grape seed proanthocyanidins against iron overloadinduced renal oxidative damage in rats. Journal of Trace Elements in Medicine and Biology, 2020. 57: p. 126407.

14. Corbe, C., J. Boissin, and A. Siou, Light vision and chorioretinal circulation. Study of the effect of procyanidolic oligomers (Endotelon). Journal francais d'ophtalmologie, 1988. 11(5): p. 453-460.

15. Gil-Cardoso, K., Ginés, I., Pinsent, M., Ardévol, A., Blay, M. and Terra, X., The coadministration of proanthocyanidins and an obesogenic diet prevents the increase in intestinal permeability and metabolic endotoxemia derived to the diet. The Journal of nutritional biochemistry, 2018. 62: p. 35-
42.

16. Ginés, I., Gil-Cardoso, K., Serrano, J., Casanova-Martí, À., Blay, M., Pinsent, M., et al., Effects of an intermittent grape-seed proanthocyanidin (GSPE) treatment on a cafeteria diet obesogenic challenge in rats. Nutrients, 2018. 10(3): p. 315.

17. Faheem, S.A., Saeed, N.M., El-Naga, R.N., Ayoub, I.M. and Azab, S.S., Hepatoprotective Effect of Cranberry Nutraceutical Extract in Non-alcoholic Fatty Liver Model in Rats: Impact on Insulin Resistance and Nrf-2 Expression. Frontiers in pharmacology, 2020. 11: p. 218-218.

18. Geissman, T.A., The chemistry of flavonoid compounds. 1962, Macmillan.

19. Park, S.W., Oh, T.Y., Kim, Y.S., Sim, H., Park, S.J., Jang, E.J., et al., Artemisia Asiatica extracts protect against ethanol-induced injury in gastric mucosa of rats. Journal of gastroenterology and hepatology, 2008. 23(6): p. 976-984.

20. Abdelwahab, S.I., Protective mechanism of gallic acid and its novel derivative against ethanol-induced gastric ulcerogenic: Involvement of immunomodulation markers, Hsp70 and Bcl-2-associated $\mathrm{X}$ protein. International immunopharmacology, 2013. 16(2): p. 296-305.

21. Bancroft, J.D. and M. Gamble, Theory and practice of histological techniques. 2008: Elsevier health sciences.

22. Ghoul, Z., Laurent, S., Boutry, S., Vander Elst, L., Nateche, F., Muller, R.N., et al., Antioxidant, antibacterial, and cell toxicity effects of polyphenols Fromahmeur beamer grape seed extracts. Journal of Fundamental and Applied Sciences, 2017. 9(1): p. 392420.

23. Ma, Z.F. and H. Zhang, Phytochemical 
constituents, health benefits, and industrial applications of grape seeds: A mini-review. Antioxidants, 2017.6(3): p. 71.

24. Anastasia, M., Chorianopoulos, N.G., Nychas, G.J.E. and Haroutounian, S.A., Antilisterial activities of polyphenol-rich extracts of grapes and vinification byproducts. Journal of Agricultural and Food Chemistry, 2009. 57(2): p. 457-463.

25. 25. Bagchi, D., Bagchi, M., Stohs, S.J., Ray, S.D., Sen, C.K. and Preuss, H.G., Cellular protection with proanthocyanidins derived from grape seeds. Annals of the New York Academy of Sciences, 2002. 957(1): p. 260270.

26. 26. Albrahim, T. and A. Robert, Renal protective effects of grape seed extract treatment against Eltroxin-induced hyperthyroidism, kidney damage, and oxidative stress in male mice. Environmental Science and Pollution Research, 2020: p. 1-9.

27. 27. Gupta, M., Dey, S., Marbaniang, D., Pal, P., Ray, S. and Mazumder, B., Grape seed extract: having potential health benefits. Journal of Food Science and Technology, 2019: p. 1-11.

28. Awaad, A.S., Al-Jaber, N.A., Moses, J.E., El-Meligy, R.M., and Zain, M.E., Antiulcerogenic activities of the extracts and isolated flavonoids of Euphorbia cuneata Vahl. Phytotherapy Research, 2013. 27(1): p. 126-130.

29. Park, S., Hahm, K.B., Oh, T.Y., Jin, J.H. and Choue, R., Preventive effect of the flavonoid, wogonin, against ethanol-induced gastric mucosal damage in rats. Digestive Diseases and Sciences, 2004. 49(3): p. 384-394.

30. Park, J.H., Jang, K.J., Kim, C.H., Kim, J.H., Kim, Y.K., and Yoon, H.M., Ganoderma lucidum pharmacopuncture for treating ethanol-induced chronic gastric ulcers in rats. Journal of pharmacopuncture, 2015. 18(1): p. 72 .

31. Sies, H., Oxidative stress: a concept in redox biology and medicine. Redox biology, 2015. 4: p. 180-183.

32. Marrocco, I., F. Altieri, and I. Peluso, Measurement and clinical significance of biomarkers of oxidative stress in humans. Oxidative medicine and cellular longevity, 2017. 2017.

33. Valko, M., Leibfritz, D., Moncol, J., Cronin, M.T., Mazur, M. and Telser, J., Free radicals and antioxidants in normal physiological functions and human disease. The international journal of biochemistry \& cell biology, 2007. 39(1): p. 44-84.

34. Antonisamy, P., Subash-Babu, P., Alshatwi, A.A., Aravinthan, A., Ignacimuthu, S., Choi, K.C., et al., Gastroprotective effect of nymphayol isolated from Nymphaea stellata (Willd.) flowers: contribution of antioxidant, anti-inflammatory, and anti-apoptotic activities. Chemico-Biological Interactions, 2014. 224: p. 157-163.

35. Zima, T. and M. Kalousová, Oxidative stress and signal transduction pathways in alcoholic liver disease. Alcoholism: Clinical and Experimental Research, 2005. 29: p. 110S-115S. 